\title{
Pulmonary Imaging of Immunocompromised Patients during Hematopoietic Stem Cell Transplantation using Non-Contrast- Enhanced Three-Dimensional Ultrashort Echo Time (3D-UTE) MRI
}

\section{Die pulmonale MRT unter Verwendung einer 3D-UTE-Sequenz zur kontrastmittelfreien Lungenbildgebung von immunsupprimierten Patienten unter Stammzelltransplantation}

\author{
Authors \\ Corona Metz $^{10}$, David Böckle², Julius Frederik Heidenreich¹, Andreas Max Weng ${ }^{1}$, Thomas Benkert ${ }^{3}$, Götz \\ Ulrich Grigoleit ${ }^{2}$, Thorsten Bley ${ }^{1}$, Herbert Köstler ${ }^{1}$, Simon Veldhoen ${ }^{1}$
}

Affiliations

1 Department of Diagnostic and Interventional Radiology, University Hospital of Würzburg, Germany

2 Department of Internal Medicine II (Hematology and Oncology), University Hospital of Würzburg, Germany

3 Application Development, Siemens Healthcare $\mathrm{GmbH}$, Erlangen, Germany

Key words

thorax, infection, ultrashort echo time, magnetic resonance imaging, pulmonary imaging, hematopoietic stem cell transplantation

received 31.12 .2020

accepted 03.06.2021

published online 14.10.2021

\section{Bibliography}

Fortschr Röntgenstr 2022; 194: 39-48

DOI 10.1055/a-1535-2341

ISSN 1438-9029

(C) 2021. Thieme. All rights reserved.

Georg Thieme Verlag KG, Rüdigerstraße 14,

70469 Stuttgart, Germany

Correspondence

Dr. Corona Metz

Diagnostic and Interventional Radiology, Universitätsklinikum Würzburg, Oberdürrbacher Straße 6, 97080 Würzburg, Germany

Tel.: +49/931/20134452

metz_c1@ukw.de

\section{ZUSAMMENFASSUNG}

Ziel Evaluation einer 3-dimensionalen MRT-Sequenz mit ultrakurzer Echozeit (3D-UTE) für die pulmonale Bildgebung immunsupprimierter Patienten unter Stammzelltransplantation.

Material und Methoden Die Datenaufnahme erfolgte mit einer 3D-UTE-Sequenz (Schichtdicke 2,34mm; Matrix
$256 \times 256$; Akquisitionszeit 12,7-17,6 s) unter Verwendung einer Stack-of-spirals-Trajektorie innerhalb eines Atemstopps. Die Untersuchungen wurden vor Beginn der Stammzelltransplantation, bei periprozeduralen Pneumonien, vor Entlassung und im Falle einer Rehospitalisierung durchgeführt. Die Datensätze wurden auf vorliegende Pleuraergüsse, Milchglasinfiltrate und Konsolidierungen von 2 Radiologen auf Lungenbasis bewertet. Zum Vergleich wurde eine klinische T2-Bildgebung herangezogen (BLADE, Schichtdicke 6,00mm; Matrix $320 \times 320$; Akquisitionszeit 3,1-5,5 min) und im Atomstopp in koronarer Schichtführung akquiriert. Klinisch indizierte Low-Dose-CT-Untersuchungen in Inspiration wurden als Referenz herangezogen und auf Lungenbasis evaluiert. Es wurden nur Untersuchungen eingeschlossen, die innerhalb von maximal 3 Tagen angefertigt wurden. Interrater-Übereinstimmung, Sensitivität, Spezifität, positiver und negativer prädiktiver Wert sowie diagnostische Genauigkeit der 3D-UTE-MRT wurden ermittelt.

Ergebnisse 67 MR-Scans von 28 Patienten wurden akquiriert. Zu 33 MRT-Untersuchungen von 23 Patienten lag eine Referenz-CT vor. Die 3D-UTE zeigte eine hohe Sensitivität und Spezifität in der Detektion von Pleuraergüssen ( $n=6$; Sensitivität $92 \%$; Spezifität $100 \%)$ und Konsolidierungen ( $n=22$; Sensitivität $98 \%$; Spezifität $86 \%$ ). Hinsichtlich Milchglasinfiltraten ( $n=9$; Sensitivität $63 \%$; Spezifität $84 \%$ ) war die diagnostische Leistungsfähigkeit geringer. Die Genauigkeit der 3D-UTE-MRT war hoch (Pleuraergüsse, $98 \%$; Milchglasinfiltrate, 79\%; Konsolidierungen, $94 \%$ ). Die Interrater-Übereinstimmung war für Pleuraergüsse und Konsolidierungen substanziell $(\kappa=0,69-0,82)$, für Milchglasinfiltrate moderat $(\kappa=0,54)$. Verglichen mit der T2-Sequenz zeigte die 3D-UTE-MRT die pulmonalen Pathologien in mindestens gleichwertiger Abbildungsqualität und wurde bei Konsolidierungen und Milchglasinfiltraten in $50 \%$ der Fälle als überlegen bewertet.

Schlussfolgerung Die kontrastmittelfreie 3D-UTE-MRT ermöglicht eine strahlungsfreie und diagnostische Darstellung typischer pulmonaler Komplikationen von Patienten unter Stammzelltransplantation. Die CT zeigte sich zur Erkennung reiner Milchglasinfiltrate überlegen. 


\section{Kernaussagen:}

- Die 3D-UTE-MRT des gesamten Thorax kann innerhalb eines Atemstopps akquiriert werden.

- Die 3D-UTE-MRT ermöglicht die diagnostische Bildgebung von Pleuraergüssen und Konsolidierungen.

- Die 3D-UTE-MRT verbessert die Detektionsraten von Milchglasinfiltraten in der pulmonalen MRT.

- Die 3D-UTE-Bildgebung stellt pulmonale Pathologien mindestens gleichwertig zur T2-Blade dar.

\section{ABSTRACT}

Purpose To evaluate the feasibility of non-contrast-enhanced three-dimensional ultrashort echo time (3D-UTE) MRI for pulmonary imaging in immunocompromised patients during hematopoietic stem cell transplantation (HSCT).

Methods MRI was performed using a stack-of-spirals 3D-UTE sequence (slice thickness: $2.34 \mathrm{~mm}$; matrix: $256 \times 256$; acquisition time: $12.7-17.6$ seconds) enabling imaging of the entire thorax within single breath-holds. Patients underwent MRI before HSCT initiation, in the case of periprocedural pneumonia, before discharge, and in the case of re-hospitalization. Two readers separately assessed the images regarding presence of pleural effusions, ground glass opacities (GGO), and consolidations on a per lung basis. A T2-weighted (T2w) multishot Turbo Spin Echo sequence (BLADE) was acquired in coronal orientation during breath-hold (slice thickness: $6.00 \mathrm{~mm}$; matrix: $320 \times 320$; acquisition time: $3.1-5.5 \mathrm{~min}$ ) and read on a per lesion basis. Low-dose CT scans in inspiration were used as reference and were read on a per lung basis. Only scans performed within a maximum of three days were included in the inter-method analyses. Interrater agreement, sensitivity, specificity, positive and negative predictive values, and diagnostic accuracy of 3D-UTE MRI were calculated.
Results $67 \mathrm{MRI}$ scans of 28 patients were acquired. A reference CT examination was available for 33 scans of 23 patients. 3D-UTE MRI showed high sensitivity and specificity regarding pleural effusions ( $n=6$; sensitivity, $92 \%$; specificity, $100 \%$ ) and consolidations ( $n=22$; sensitivity $98 \%$, specificity, $86 \%$ ). Diagnostic performance was lower for GGO ( $n=9$; sensitivity, $63 \%$; specificity, $84 \%$ ). Accuracy rates were high (pleural effusions, $98 \%$; GGO, $79 \%$; consolidations 94\%). Interrater agreement was substantial for consolidations and pleural effusions $(\mathrm{K}=0.69-0.82)$ and moderate for GGO $(\mathrm{K}=0.54)$. Compared to T2w imaging, 3D-UTE MRI depicted the assessed pathologies with at least equivalent quality and was rated superior regarding consolidations and GGO in 50\%.

Conclusion Non-contrast 3D-UTE MRI enables radiation-free assessment of typical pulmonary complications during HSCT procedure within a single breath-hold. Yet, CT was found to be superior regarding the identification of pure GGO changes.

\section{Key Points:}

- 3D-UTE MRI of the thorax can be acquired within a single breath-hold.

- 3D-UTE MRI provides diagnostic imaging of pulmonary consolidations and pleural effusions.

- 3D-UTE sequences improve detection rates of ground glass opacities on pulmonary MRI.

- 3D-UTE MRI depicts pulmonary pathologies at least equivalent to T2-weighted Blade sequence.

\section{Citation Format}

- Metz C, Böckle D, Heidenreich JF et al. Pulmonary Imaging of Immunocompromised Patients during Hematopoietic Stem Cell Transplantation using Non-Contrast-Enhanced Three-Dimensional Ultrashort Echo Time (3D-UTE) MRI. Fortschr Röntgenstr 2022; 194: 39-48

\section{Introduction}

Pneumonia is an important cause of morbidity and mortality in immunocompromised patients with hematopoietic disease, in particular during hematopoietic stem cell transplantation (HSCT) procedure. Depending on the underlying spectrum of pathogens, nodules, consolidations, and areas of ground glass opacity (GGO) are common findings in pulmonary imaging during respiratory infections. Non-infectious complications, such as alveolar hemorrhage, bronchiolitis, or cryptogenic pneumonia, lead to structural changes of the lung parenchyma [1]. CT is the established reference technique to assess inflammatory or structural changes in the lungs [2-4]. Repeated CT imaging in episodes of pneumonia during HSCT procedure is commonly necessary, resulting in a high cumulative radiation dose, which is undesirable especially in younger patients $[5,6]$.

Due to recent technical advances, MRI, which is free of exposure to ionizing radiation, has become a competitor to $\mathrm{CT}$ regarding imaging of pulmonary pathologies [7-9]. Historically, the use of MRI for pulmonary imaging has been hampered by low parenchy- mal proton density, short $\mathrm{T}^{*}(0.8-3 \mathrm{msec}$ at clinical field strengths), and image artifacts from respiratory and cardiac motion [10]. Using echo times of $\sim 0.2 \mathrm{msec}$ - being well below parenchymal T2* - MRI sequences with ultrashort echo time (UTE) allow for a significantly increased signal yield [11]. To date, three-dimensional (3D) UTE sequences provide whole-chest coverage with low susceptibility to motion artifacts [12]. Pilot studies reported comparable diagnostic performance of UTE MRI and CT regarding pulmonary imaging for the detection of pulmonary nodules [13-16] and for parenchymal diseases [17]. A limitation of the aforementioned study of Ohno et al. [17] was the different breathing depth between $C T$ acquired in inspiration and the $3 \mathrm{D}$ radial UTE MRI with respiratory gating to expiration limiting comparability. 3D-UTE MRI in breath-hold technique allows for rapid acquisition of different breathing depths enabling their comprehensive comparison regarding the quality of morphologic imaging.

The purpose of this study was to evaluate the feasibility of noncontrast-enhanced 3D-UTE MRI acquired in breath-hold for pulmonary imaging in immunocompromised patients during HSCT procedure. 


\section{Materials and Methods}

\section{Institutional Review}

The institutional review board approved this study. All patients provided written informed consent prior to the examinations.

\section{Study protocol}

Patients undergoing allogeneic HSCT due to a hematopoietic disease were included in this prospective single-center study. The inclusion criteria were planned HSCT, available baseline CT before HSCT initiation, and informed consent. The exclusion criteria were general contraindications for MRI, unavailable baseline $\mathrm{CT}$, insufficient general condition at baseline, or informed consent refusal.

Each patient underwent pulmonary 3D-UTE MRI at hospitalization before HSCT initiation, in the case of CT-proven pneumonia, and before discharge after the completion of HSCT. Additional 3D-UTE MRI was acquired in the case of re-hospitalization within six months after HSCT. At each time point, a T2-weighted (T2w) multi-shot Turbo Spin Echo sequence with periodically rotated overlapping parallel lines with enhanced reconstruction (BLADE, Siemens Healthcare) was acquired as the clinical MRI reference.

The HSCT protocol at our clinic includes a non-contrastenhanced thoracic low-dose CT scan before HSCT initiation, which was used as the reference standard at baseline. Typical indications for periprocedural low-dose CT were clinical suspicion or monitoring of pulmonary infections and suspicion of pulmonary pathology at sudden oxygen demand. If additional CT examinations were performed around discharge or at re-hospitalization within six months after HSCT for clinical reasons, they were used as reference examinations as well. To reduce the influence of the time interval between CT and MRI scans on the method comparison, only examinations performed within a maximum time interval of three days between MRI and CT were included in the intermethod analyses. For interrater agreement analysis and in-method comparisons, all acquired MRI examinations were included.

\section{MR imaging protocol and image reconstruction}

Data were acquired on a 3 Tesla system (MAGNETOM Prisma, Siemens Healthcare) equipped with an 18-channel body and a 32-channel spine coil using a prototypical 3D-UTE sequence employing a stack-of-spirals trajectory $[18,19]$ with single breath-hold acquisition. General sequence parameters are summarized in $>$ Table 1. Specific sequence parameters were set as follows: non-selective RF excitation pulse, coronal slice orientation, number of spiral readouts per partition $=264$; number of partitions acquired with 256 spiral arms each: $102 \pm 14$ (depending on the thoracic diameter). Surface coil intensity was corrected by performing normalization based on a low-resolution body coil image. Since the outer parts of k-space were undersampled in this highly accelerated acquisition, images were reconstructed using an iterative algorithm $[18,20]$.

Images were acquired in tidal inspiration and tidal expiration to investigate the impact of different breathing states on image quality. Breathing maneuvers were instructed via headphones. A
- Table 1 MR imaging parameters.

- Tab. 1 Sequenzspezifische Parameter.

\begin{tabular}{|c|c|c|}
\hline & 3D-UTE & $\begin{array}{l}\text { T2w sequence } \\
\text { (BLADE) }\end{array}$ \\
\hline repetition time (msec) & 2.35 & 1400 \\
\hline echo time (msec) & 0.05 & 90 \\
\hline $\mathrm{FA}^{\circ}$ & 5 & 135 \\
\hline matrix & $256 \times 256$ & $320 \times 320$ \\
\hline FoV $\left(\mathrm{mm}^{2}\right)$ & $600 \times 600$ & $400 \times 400$ \\
\hline slice thickness (mm) & 2.34 & 6.00 \\
\hline slice orientation & coronal, sagittal, axial & coronal \\
\hline acquisition time & $12.7-17.6 \mathrm{~s}$ & $3.1-5.5 \mathrm{~min}$ \\
\hline \multicolumn{3}{|c|}{$\begin{array}{l}\text { BLADE: proprietary name for periodically rotated overlapping parallel } \\
\text { lines with enhanced reconstruction in MR systems by Siemens Health- } \\
\text { care; FA: flip angle; FoV: field of view; UTE: ultrashort echo time; T2w: } \\
\text { T2-weighted. }\end{array}$} \\
\hline
\end{tabular}

single dataset of the thorax was obtained during a breath-hold time of 12.7-17.6s depending on the individual thoracic diameter. Accordingly, the overall examination time including both breathing levels and a pause in between was less than 1 minute.

The T2w BLADE sequence was acquired in coronal orientation with an acquisition time of 3.1-5.5 min and a breath-hold time of $15-18 \mathrm{~s}$ with $6-10$ concatenations. Further image parameters are summarized in $>$ Table 1.

\section{CT protocol}

All chest CTs were performed with a 64-detector single-source system (Somatom Definition AS, Siemens Healthcare), a 128-detector twin-beam system (Somatom Definition Edge, Siemens Healthcare) or a 364-detector dual-source system (Somatom Force, Siemens Healthcare) at full inspiration. Non-contrast-enhanced images were obtained at 50-150 reference mAs and 100-120 kV (depending on system). Dose modulation systems were used. The average examination time was 3-8 s. Images were reconstructed at slice thicknesses of $1 \mathrm{~mm}, 3 \mathrm{~mm}$, and $10 \mathrm{~mm}$ (MIP) and assessed in a lung window (width, $1500 \mathrm{HU}$; center, $-400 \mathrm{HU}$ ).

\section{Qualitative Assessment}

All 3D-UTE MR image sets were anonymized, randomized, and separately reviewed by two radiologists with eight and two years of experience in thoracic MRI (S.V., C.M.) on a per lung basis regarding the presence of pleural effusions, GGO, and pulmonary consolidations. Images were reviewed on an acquired inspiration and an expiration breath-hold level and the visibility of a certain pathology was compared on a three-point scale (better/equal/ worse). $3 \mathrm{D}$ imaging allows any desired orientation by using multiplanar reconstruction. Images were read on a clinical workstation using a commercially available picture archiving and communication system (Phoenix-PACS). Each CT image used as the reference 
standard was evaluated, anonymized, and randomized regarding the same study items in consensus reading on a per lung basis using all three slice orientations. Therefore, 3D-UTE MRI and CT image sets were first read on coronal slices and proofread on sagittal and axial planes. For image assessment, standardized terms for thoracic imaging as proposed by the Fleischner Society were used for CT [21] and adopted for MRI [22]. Visibility of a certain pathology in 3D-UTE MRI was compared to the corresponding image set of the T2w sequence in coronal slice orientation on a three-point scale (better/equal/worse) on a per lesion basis.

\section{Statistical Analyses}

Statistical tests were performed using SPSS Version 25 (IBM). The sensitivity, specificity, PPV, NPV as well as accuracy rates of MRI were calculated. The Wilcoxon signed-rank test was used for comparison of 3D-UTE MRI and CT. Cohen's Kappa test assessed the interrater agreement in 3D-UTE MRI. Continuous variables are reported as mean \pm standard deviation. Statistical significance was set at $p<0.05$.

\section{Results}

Pulmonary 3D-UTE MRI was performed successfully in all patients without periprocedural complications.

\section{Study sample}

During the study period, 24 patients were excluded due to contraindications for MRI $(n=2)$, refusal of participation $(n=19)$, or insufficient general condition $(n=3) .28$ patients (mean age \pm standard deviation, $60 \pm 11$ years; median age, 58.5 years; range, 22-78 years; 20 men) undergoing allogeneic HSCT due to a hematopoietic disease (myelodysplastic syndrome, $n=11$; acute myeloid leukemia, $n=11$; acute lymphoblastic leukemia, $n=2$; chronic myeloid leukemia, $n=1$; proliferative myelofibrosis, $n=2$; multiple myeloma, $n=1$ ) were included, and a total of 67 pulmonary MRI scans was performed. Each patient $(n=28)$ received pulmonary 3D-UTE MRI at hospitalization and 21 patients before discharge. 6 patients died prior to discharge, and one refused to consent to further MRI scans. 12 MRI scans were periprocedural scans performed in 10 patients. 2 patients received 2 periprocedural scans. The remaining 6 scans were performed at re-hospitalization of 6 patients.

As only examinations with a corresponding CT scan acquired within a maximum time interval of three days or less were included in the analyses, 33 scans of 23 patients matched this criterion. 19 of those scans were performed at hospitalization before HSCT with a mean interval of $0.9 \pm 0.7$ days (median: $1.0 \mathrm{~d}$; range: $0-3 \mathrm{~d}$ ) and 4 scans before discharge with a mean interval of 1.5 \pm 1.5 days (median: $1.5 \mathrm{~d}$; range, $0-3 \mathrm{~d}$ ). 8 scans were periprocedural examinations of 6 patients within a mean interval of 1.3 $\pm 0.7 \mathrm{~d}$ (median, $1.0 \mathrm{~d}$; range, $0-3 \mathrm{~d}$ ). Two patients were scanned at re-hospitalization within six months (mean time interval: 2.0 $\pm 1.0 \mathrm{~d}$; median: $2.0 \mathrm{~d}$; range: $1-3 \mathrm{~d}$ ). 9 of those 33 CT scans were consensus rated as being free of pathologies, the remaining 24 scans showed at least one of the mentioned findings: 6 scans
(4 patients) showed pleural effusions, 8 scans (7 patients) GGOs and 22 scans (13 patients) pulmonary consolidations.

\section{Comparison of 3D-UTE MRI and CT}

The comparison of 3D-UTE MRI and CT revealed no significant differences regarding the detection rates of pleural effusions (observer 1, p = 0.32; observer 2, p>0.99), GGOs (observer 1, $p=0.74$; observer $2, p=0.41$ ), and consolidations (observer 1 , $p>0.99$; observer 2, $p=0.16$ ) for both readers.

Based on CT scans as reference examinations, the sensitivity, specificity, PPV, and NPV of 3D-UTE MRI as well as the diagnostic accuracy between MRI and CT regarding the reviewed pathologies are listed separately for each reader in $\boldsymbol{\nabla}$ Table 2 . Pleural effusions showed a mean sensitivity of $92 \pm 14 \%$ (PPV: $100 \pm 0 \%$ ) with 5/6 (observer 1) and 6/6 (observer 2) true positives. One observer rated one patient false negative for pleural effusions, but in that case the pleural effusion showed a very low extent of only up to $7 \mathrm{~mm}$. For GGO, the mean sensitivity was $63 \pm 15 \%$ and the mean PPV was $52 \pm 9 \%$ with $4 / 9$ (observer 1 ) and 6/9 (observer 2 ) true positives. The highest sensitivity was achieved for pulmonary consolidations with a mean of $89 \pm 10 \%$ (true positive: observer 1, 21/ 22 ; observer 2, 22/22) and a mean PPV of $94 \pm 5 \%$. The specificity values were high with $100 \pm 0 \%$ for pleural effusions (true negative: observer $1+2,27 / 27$ ), $84 \pm 3 \%$ for GGOs (true negative: observer 1, 20/24; observer 2, 22/24), and $83 \pm 9 \%$ (true negative: observer $1,10 / 11$; observer $2,9 / 11$ ) for consolidations. The mean accuracy between 3D-UTE MRI and CT was best regarding pleural effusions with $98 \pm 3 \%$. It reached $79 \pm 3 \%$ for GGOs and $94 \pm 8 \%$ for consolidations. Imaging examples of the assessed pathologies on CT, 3D-UTE MRI, and the T2w BLADE sequence are given in - Fig. $1,2$.

\section{Interrater agreement in 3D-UTE MRI}

A total of 67 scans were available for interrater agreement analyses. The best interrater agreement was found for pleural effusions with a mean Cohen's Kappa ( $\mathrm{k}$ ) of 0.82 . The mean $\mathrm{k}$ was 0.54 for GGOs and 0.69 for pulmonary consolidations. - Table 3 provides detailed results of the interrater agreement analyses.

\section{Qualitative assessment of 3D-UTE MRI and T2- weighted imaging}

Regarding the comparison of inspiration and expiration acquired in 3D-UTE MRI, both readers did not find a breathing level to provide constant superior or inferior illustration of the lung pathologies assessed. - Table 4 presents detailed results of both observers regarding comparison of the visibility of the mentioned findings in inspirational and expirational breath-hold level.

Both radiologists rated all detected pathologies with equal or superior visibility in 3D-UTE MRI when compared to the T2w sequence. - Table 5 presents detailed results of both observers.

\section{Discussion}

This prospective study evaluated the feasibility of three-dimensional ultrashort echo time (3D-UTE) MRI acquired within a single 


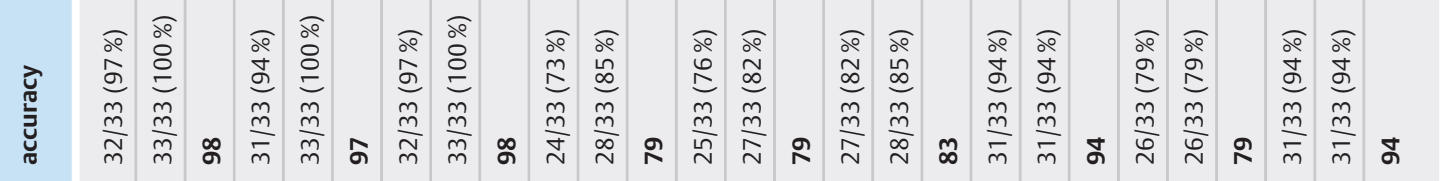

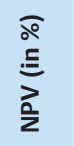

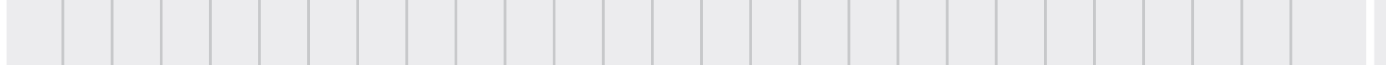

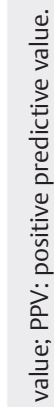

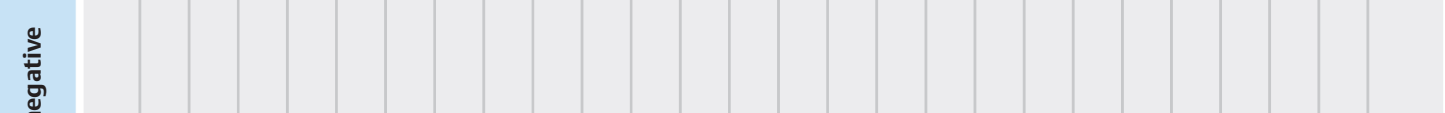

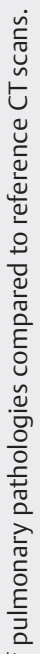

$\stackrel{\check{n}}{\frac{\pi}{n}}$

คำ

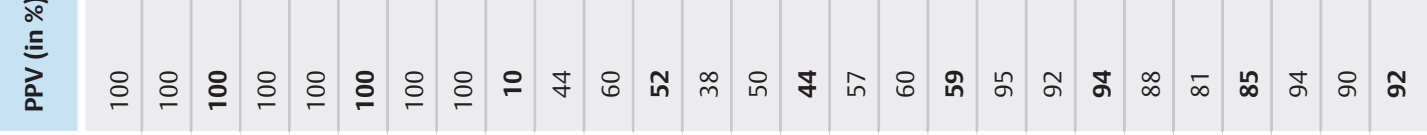

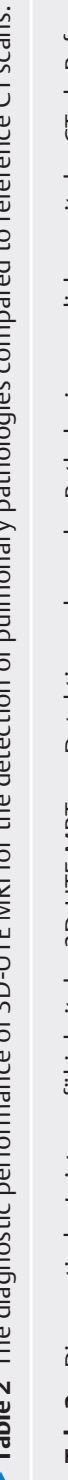

$\sum_{\text {ì }}^{n}$

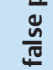

10

कำ

$\stackrel{\circ}{\leqq}$

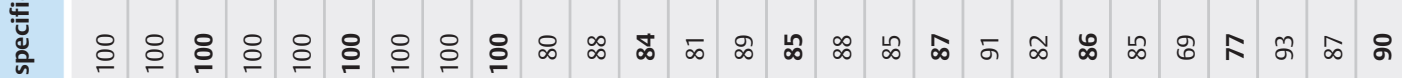
(a)

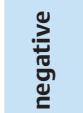

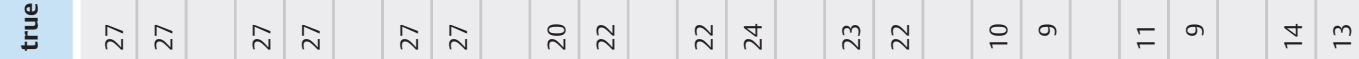

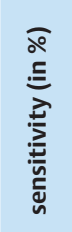

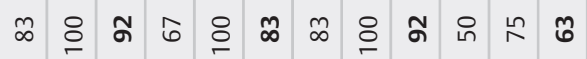

in in in in $\infty \pi$ ณ

舟

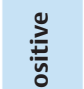

อับ

ก 6 (

0

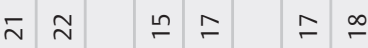

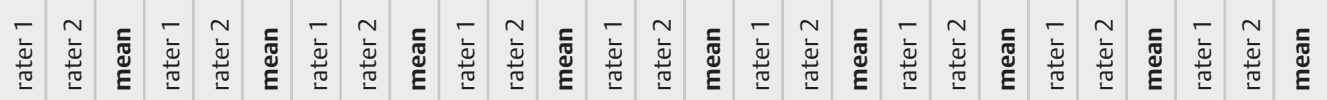

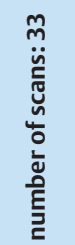

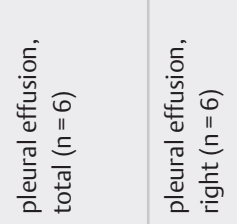

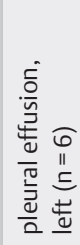

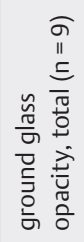

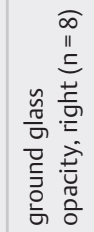

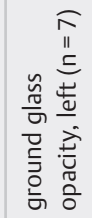

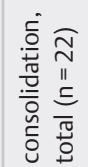

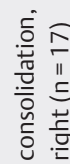

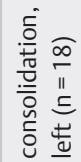




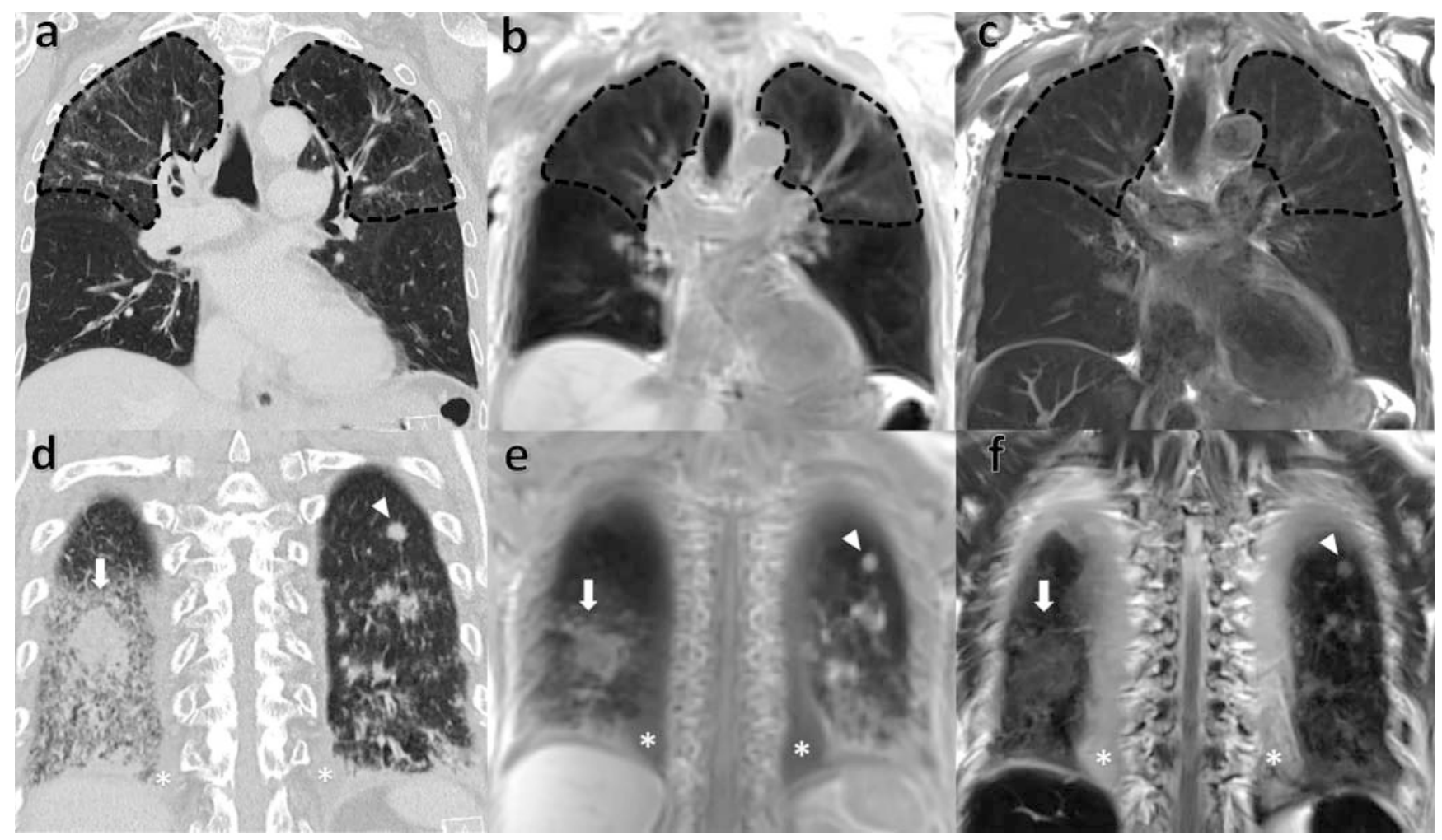

- Fig. 1 a, d Low-dose CT of a 64-year-old woman with acute myeloid leukemia. Diffuse ground glass opacities (dashed lines) in both upper lobes, nodules (arrowhead) and consolidations (big arrow), were detected by CT and $\mathbf{b}$, e three-dimensional ultrashort echo time (3D-UTE) MRI. Regarding ground glass opacities, 3D-UTE provided superior identifiability compared to the $\mathbf{c}, \mathbf{f} \mathrm{T} 2$-weighted sequence. For nodules and consolidations, the sequences performed similarly. Pleural effusions (asterisk) on both sides were visible on CT (soft tissue window not presented) as well as in 3DUTE and T2-weighted BLADE sequence.

- Abb. 1 a, d Low-dose-CT einer 64-jährigen Frau mit akuter myeloischer Leukämie. Diffuse Milchglasinfiltrate (gestrichelte Linien) in beiden Lungen, Noduli (Pfeilspitze) und Konsolidierungen (dicker Pfeil) konnten mittels CT und b, e 3-dimensionaler Ultra-short-echo-time (3D-UTE) -MRT detektiert werden. Bezüglich Milchglasinfiltraten zeigte sich die 3D-UTE verglichen zur c, f T2-gewichteten Sequenz überlegen. Die Detektierbarkeit von Noduli und Konsolidierungen war in beiden Sequenzen vergleichbar. Pleuraergüsse (Stern) beidseits waren sowohl in der CT (Weichteilfenster nicht präsentiert) als auch in der 3D-UTE und der T2-gewichteten BLADE-Sequenz sichtbar.

breath-hold for diagnostic imaging of pulmonary complications during hematopoietic stem cell transplantation procedure.

UTE MRI allows for whole-chest coverage in $3 \mathrm{D}$ at any desired breathing level within a single breath-hold, making the overall examination time comparable to that of a chest $\mathrm{CT}$. With $\mathrm{CT}$ as the reference standard, 3D-UTE MRI provided overall high diagnostic accuracy (81-98\%), specificity (83-100\%), and NPV (84$97 \%$ ) regarding the detection of the assessed pulmonary pathologies. Sensitivity and PPV were distinctly lower for GGOs (51$61 \%$ ) compared to consolidations ( $88-89 \%$ ) and pleural effusions $(88-100 \%)$. Interrater agreement in 3D-UTE MRI was substantial except for GGOs, where the agreement level was moderate. Compared to the assessed T2-weighted BLADE sequence, 3D-UTE MRI provided at least equal illustration of the investigated pulmonary pathologies and was rated superior in approximately $50 \%$ of consolidations and GGOs. No particular breathing state provided consistently better or worse detectability of the assessed findings in 3D-UTE MRI, indicating that the acquisition of a single breathing state might be satisfactory for pulmonary imaging using the assessed UTE sequence.
Many authors proposed lung MRI as a radiation-free alternative to $C T$, especially for follow-up studies in younger patients $[23,24]$, and previous studies demonstrated sufficient diagnostic accuracy of MRI for the detection of pneumonia in neutropenic patients $[6,25,26]$. For instance, the study of Attenberger et al. [22] showed an overall accuracy of lung MRI of $88 \%$ regarding several pulmonary abnormalities when compared to $\mathrm{CT}$ as the reference. In their study, a finding was rated positive when at least one of the acquired sequences within the used MRI protocol ( $T 2 \mathrm{w}$ HASTE, 3 D VIBE) detected it. Similar results with mean consistencies of 79-98\% were achieved in the present study but with a single contrast-free sequence acquired during a single breath-hold, thus providing a significantly reduced acquisition time of pulmonary MRI. In contrast to the studies of Rieger et al. [27] and Ohno et al. [17], the present study protocol also included normal scans without any pathology.

With a sensitivity of $35 \%$, Attenberger et al. postulated the detection of GGOs to be a major limitation of 3 T MRI [22]. Although the performance of 3D-UTE MRI for the detection of GGOs with a mean sensitivity of up to $61 \%$ and a mean PPV of up 


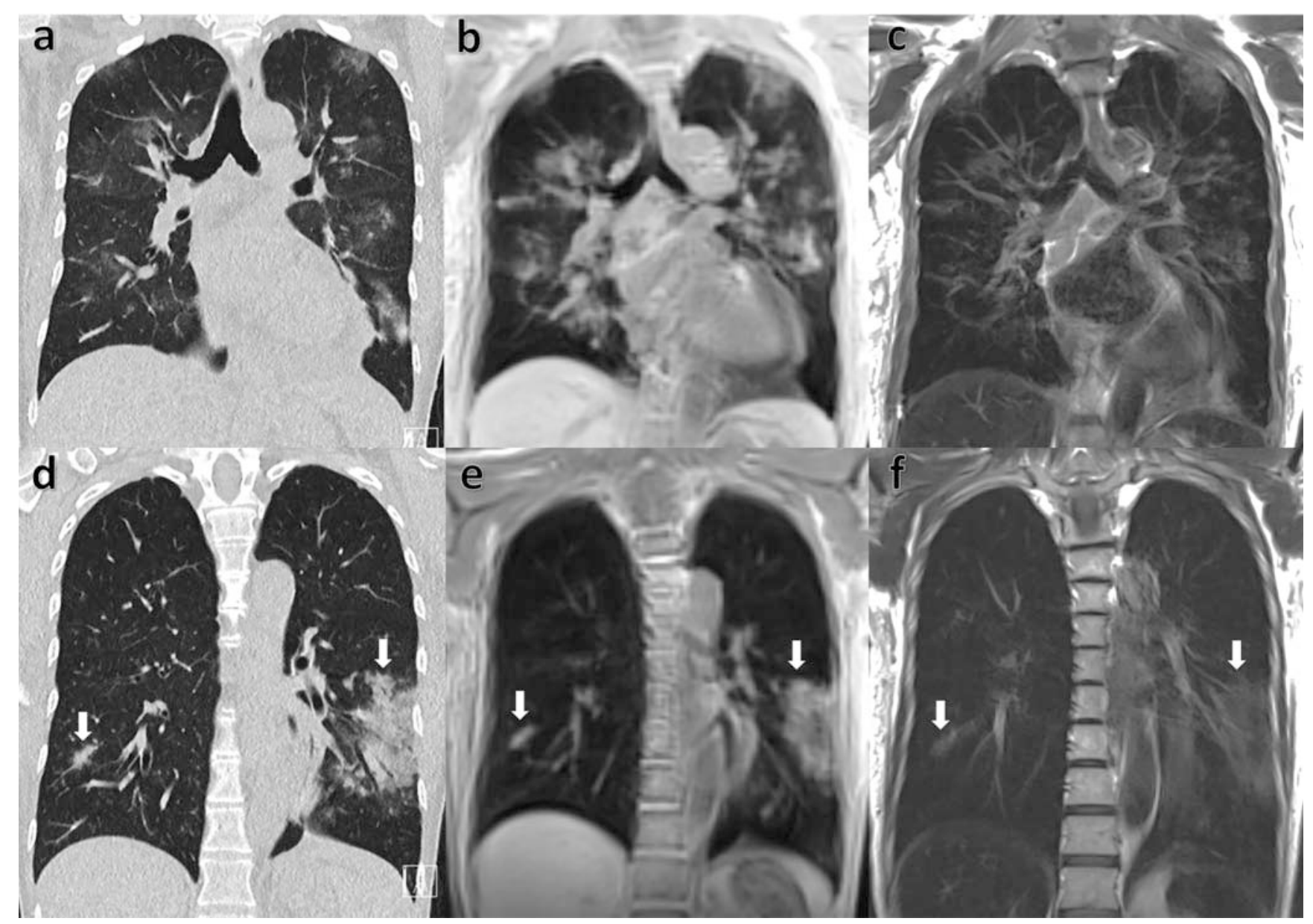

- Fig. 2 a Low-dose CT of a 50-year-old woman with acute myeloid leukemia. The CT image shows diffuse areas of ground glass opacity, presenting superior on thoracic $\mathbf{b}$ three-dimensional ultrashort echo time (3D-UTE) MRI compared to $\mathbf{c}$ T2-weighted sequence. $\mathbf{d}$ Low-dose CT of the same patient six months later. The CT image demonstrates extensive consolidations in the lower lobe of both sides (arrow). These findings are equally represented on e 3D-UTE MRI. f T2-weighted sequence BLADE is inferior regarding illustration of the consolidations when compared to 3D-UTE MRI.

- Abb. 2 a Low-dose-CT einer 50-jährigen Frau mit akuter myeloischer Leukämie. Das CT zeigt diffuse Milchglasareale, welche im Vergleich zur c T2-gewichteten BLADE-Sequenz in der b 3-dimensionalen Ultra-short-echo-time (3D-UTE) deutlicher dargestellt wurden. d Low-dose-CT derselben Patientin 6 Monate später. Das CT zeigt ausgedehnte Konsolidierungen der Unterlappen beidseits (Pfeil), welche gleichwertig in der e 3D-UTE dargestellt wurden. f Die T2-gewichtete BLADE-Sequenz war in der Darstellung der Konsolidierungen im Vergleich zur 3D-UTE unterlegen.

to $51 \%$ was superior when compared to the results of Attenberger et al. and Ekinci et al. [6], it was still significantly lower when compared to $\mathrm{CT}$ as the reference. However, only three of the investigated 28 patients in our study showed exclusive GGOs without concomitant consolidations on CT. The more experienced observer correctly recognized one of these. The other two were missed by both readers. In the first patient, MR and CT image assessment was highly hampered by motion artifacts but CT was still able to visualize the areas of GGO. The CT image set of the second patient showed a single and very discrete focal ground glass area, which could only be assumed on MRI with knowledge of the CT finding and was missed by both readers. In seven other patients (eleven scans), GGO was accompanied by consolidations, and only one of these scans was missed by one observer. Thus, the clinical importance of the detection of pure GGOs remains questionable in the context of diagnostic imaging during HSCT and needs a larger study population for a targeted investigation.
Generally, lower respiratory tract infections can cause intrapulmonary and extrapulmonary complications and are associated with high morbidity and mortality rates in immunocompromised patients. Early diagnosis and therapy of pneumonia as well as early detection of its partly life-threatening complications can have severe impact on patient outcome $[28,29]$. Parapneumonic effusion is such a complication occurring in $20-40 \%$ of patients and raising the mortality rate compared to patients without effusion [30]. 3D-UTE MRI enables diagnostic imaging of pleural effusions and consolidations as well as any number of follow-up scans to assess the therapy response in a radiation-free manner.

\section{Limitations}

The study has a limited number of patients. As was to be expected, the consent of the partly critical ill patients to additional MRI examinations for study purposes was moderate, especially under the circumstances of periprocedural complications during HSCT. To avoid 
- Table 3 Interrater agreement of 3D-UTE MRI.

- Tab.3 Interrater Übereinstimmung in der 3D-UTE-MRT.

\begin{tabular}{|l|c|c|c|}
\hline number of scans: $\mathbf{6 7}$ & frequency of finding & Cohen's Kappa \\
\hline & observer 1 & observer 2 & \\
\hline pleural effusion, right lung & 7 & 9 & 0.86 \\
\hline pleural effusion, left lung & 6 & 9 & 0.78 \\
\hline ground glass opacity, right lung & 13 & 12 & 0.46 \\
\hline ground glass opacity, left lung & 12 & 14 & 0.62 \\
\hline consolidation, right lung & 30 & 37 & 0.73 \\
\hline consolidation, left lung & 29 & 35 & 0.64 \\
\hline
\end{tabular}

- Table 4 Comparison of the visibility of pulmonary pathologies in inspiration and expiration in the 3D-UTE sequence.

- Tab.4 Vergleich der Erkennbarkeit pulmonaler Pathologien in Inspiration und Exspiration der 3D-UTE-Sequenz.

\begin{tabular}{|c|c|c|c|c|}
\hline \multicolumn{2}{|c|}{ number of scans, 67} & \multirow{2}{*}{$\begin{array}{l}\text { equal } \\
66(99 \%)\end{array}$} & \multirow{2}{*}{$\begin{array}{l}\text { inspiration superior } \\
1(1 \%)\end{array}$} & \multirow{2}{*}{$\begin{array}{l}\text { expiration superior } \\
0(0 \%)\end{array}$} \\
\hline pleural effusions & observer 1 & & & \\
\hline & observer 2 & 65 (97\%) & $1(1 \%)$ & $1(1 \%)$ \\
\hline \multirow[t]{2}{*}{ GGO } & observer 1 & 65 (97\%) & $2(3 \%)$ & $0(0 \%)$ \\
\hline & observer 2 & 61 (91\%) & $4(6 \%)$ & $2(3 \%)$ \\
\hline \multirow[t]{2}{*}{ consolidations } & observer 1 & 63 (95\%) & $1(1 \%)$ & $3(4 \%)$ \\
\hline & observer 2 & $62(93 \%)$ & $3(4 \%)$ & $2(3 \%)$ \\
\hline
\end{tabular}

- Table 5 Comparison of the visibility of pulmonary pathologies in 3D-UTE and T2-weighted BLADE sequences.

- Tab.5 Vergleich der Erkennbarkeit pulmonaler Pathologien bei Verwendung der 3D-UTE und einer T2-gewichteten BLADE-Sequenz.

\begin{tabular}{|c|c|c|c|c|}
\hline \multicolumn{2}{|c|}{ number of scans, 67} & \multirow{2}{*}{$\begin{array}{l}\text { equal } \\
42(63 \%)\end{array}$} & \multirow{2}{*}{$\begin{array}{l}\text { UTE superior } \\
17(25 \%)\end{array}$} & \multirow{2}{*}{$\begin{array}{l}\text { T2w superior } \\
8(12 \%)\end{array}$} \\
\hline pleural effusions & observer 1 & & & \\
\hline & observer 2 & $67(100 \%)$ & $0(0 \%)$ & $0(0 \%)$ \\
\hline \multirow[t]{2}{*}{ GGO } & observer 1 & $27(40 \%)$ & 35 (53\%) & $5(7 \%)$ \\
\hline & observer 2 & $46(69 \%)$ & $21(31 \%)$ & $0(0 \%)$ \\
\hline \multirow[t]{2}{*}{ consolidations } & observer 1 & 30 (45 \%) & 35 (53\%) & $2(2 \%)$ \\
\hline & observer 2 & 39 (58 \%) & 27 (40\%) & $1(2 \%)$ \\
\hline
\end{tabular}

compromising data accuracy for the method comparison, examinations with a time interval of more than three days between MRI and CT were excluded, resulting in a limited number of available scans. Because a CT scan no older than six weeks is required for HSCT initiation, these scans are commonly performed elsewhere in advance, which led to a long time interval until 3D-UTE MRI and nine scans had to be excluded for this reason. Regarding periprocedural scans, four patients could not be investigated with 3D-UTE 
MRI for study purposes within three days due to their critical condition. Around discharge and in the case of re-hospitalization within six months, there was no clinical indication for further radiation exposure by $C T$, leading to a small number of reference $C T$ scans at that time point. The method comparison of 3D-UTE MRI and CT based on a maximum time interval of up to three days between the examinations may have been affected by the fact that pulmonary infiltrates and especially GGOs can be subject to rapid changes. Thus, it is possible that some of the CT findings have improved or disappeared before MRI acquisition. Therefore, it is conceivable that the study results underestimate the diagnostic accuracy of pulmonary 3D-UTE MRI. The desirable analysis of same-day examinations only could not be performed due to the limited study population.

Since the low study population is also associated with a partly low prevalence of some assessed pathologies, careful interpretation of the represented features is necessary.

As 3D-UTE MRI was rated on a per lung basis, it is possible that not every lesion was detected. However, the clinical impact of that possibly missing information is low as the therapy concept would not have changed.

The difference in slice thickness between the T2w BLADE sequence $(6 \mathrm{~mm})$ and 3D-UTE MRI $(2.3 \mathrm{~mm})$ hampers the comparison of these sequences. However, we wanted to compare the UTE technique with a clinically widespread sequence for pulmonary MRI. Reducing the slice thickness in the $\mathrm{T} 2 \mathrm{w}$ sequence in order to optimize comparability would have further increased its acquisition time, breath-hold duration and/or number of breathhold repetitions not being suitable for respiratory-compromised patients. Using 3D-UTE MRI, partitions of $2.3 \mathrm{~mm}$ can be acquired within a single breath-hold and an acquisition time of a few seconds. However, a breath-hold duration of up to $17.6 \mathrm{~s}$ can be challenging, especially for respiratory-limited persons. Further development is required to shorten the breath-hold duration.

Additionally, the T2w Blade sequence was only acquired and assessed in coronal slice orientation, which is not ideal for detecting pleural effusions, whereas the 3D-UTE sequence was assessed using all three slice orientations due to its three-dimensionality.

Another limitation of the study might be that acute graftversus-host-disease (GvHD), which demonstrates with patchy consolidations, is difficult to differentiate from pulmonary infiltrations with imaging only. However, acute pulmonary GvHD is a rare complication and none of our patients had clinical evidence of that complication.

\section{Conclusion}

Stack-of-spirals 3D-UTE MRI with single breath-hold acquisition has high potential for morphologic lung imaging to assess typical pulmonary complications during hematopoietic stem cell transplantation. 3D-UTE sequences improve detection rates of GGO in pulmonary MRI. Compared to the T2w BLADE sequence, 3D-UTE MRI provides superior illustration of the assessed pulmonary pathologies. Thus, radiation-free, contrast-free, and rapidly acquirable 3D-UTE MRI can be expected to play a major role in future pulmonary imaging, for example, in the diagnosis and follow-up of patients with pneumonia.

\section{Clinical impact}

- 3D-UTE MRI enables radiation- and contrast-free pulmonary imaging within a single breath-hold.

- Due to its diagnostic performance in the detection of lung consolidations and pleural effusions, as well as the improved detectability of ground glass opacities compared to traditional lung MRI, 3D-UTE MRI may play an important role in future pulmonary imaging.

- Patients requiring recurrent imaging may benefit from this sequence technique as a result of the reduction of the cumulative radiation dose.

\section{Funding}

Deutsche Forschungsgemeinschaft (VE1008/1-1, KO 2938/5-1)

The Department of Diagnostic and Interventional Radiology receives a research grant from Siemens Healthcare $\mathrm{GmbH}$. The grant is not specifically directed towards any of the authors.

\section{Conflict of Interest}

The authors declare that they have no conflict of interest. We have to declare that the department of Diagnostic and Interventional Radiology, Würzburg, receives a research grant from Siemens Healthcare $\mathrm{GmbH}$. The grant is not specifically directed towards any of the authors.

\section{References}

[1] Diab M, ZazaDitYafawi J, Soubani AO. Major Pulmonary Complications After Hematopoietic Stem Cell Transplant. Exp Clin Transplant 2016; 14: 259-270

[2] Richenberg J, Harvey $\mathrm{C}$. The utility of $\mathrm{CT}$ in imaging chest infections in HIV-negative patients. Curr Opin Pulm Med 1999; 5: 179-184

[3] Young AY, Leiva Juarez MM, Evans SE. Fungal Pneumonia in Patients with Hematologic Malignancy and Hematopoietic Stem Cell Transplantation. Clin Chest Med 2017; 38: 479-491

[4] De Pauw B, Walsh T], Donnelly JP et al. Revised definitions of invasive fungal disease from the European Organization for Research and Treatment of Cancer/Invasive Fungal Infections Cooperative Group and the National Institute of Allergy and Infectious Diseases Mycoses Study Group (EORTC) MSG) Consensus Group. Clin Infect Dis 2008; 46: 1813-1821

[5] Brenner DJ, Hall EJ. Computed tomography-an increasing source of radiation exposure. N Engl J Med 2007; 357: 2277-2284

[6] Ekinci A, Yucel Ucarkus T, Okur A et al. MRI of pneumonia in immunocompromised patients: comparison with CT. Diagn Interv Radiol 2017; 23: $22-28$

[7] Johns CS, Swift AJ, Rajaram S et al. Lung perfusion: MRI vs. SPECT for screening in suspected chronic thromboembolic pulmonary hypertension. J Magn Reson Imaging 2017; 46: 1693-1697

[8] Veldhoen S, Weng AM, Knapp J et al. Self-gated Non-Contrast-enhanced Functional Lung MR Imaging for Quantitative Ventilation Assessment in Patients with Cystic Fibrosis. Radiology 2017; 283: 242-251

[9] Sodhi KS, Sharma M, Lee EY et al. Diagnostic Utility of 3T Lung MRI in Children with Interstitial Lung Disease: A Prospective Pilot Study. Acad Radiol 2018; 25: 380-386

[10] Wielputz MO, Triphan SMF, Ohno Y et al. Outracing Lung Signal Decay Potential of Ultrashort Echo Time MRI. Rofo 2019; 191: 415-423 
[11] Yu J, Xue Y, Song HK. Comparison of lung T2* during free-breathing at $1.5 \mathrm{~T}$ and 3.0 T with ultrashort echo time imaging. Magn Reson Med 2011; 66: 248-254

[12] Higano NS, Fleck RJ, Spielberg DR et al. Quantification of neonatal lung parenchymal density via ultrashort echo time MRI with comparison to CT. J Magn Reson Imaging 2017; 46: 992-1000

[13] Ohno Y, Koyama H, Yoshikawa T et al. Standard-, Reduced-, and No-Dose Thin-Section Radiologic Examinations: Comparison of Capability for Nodule Detection and Nodule Type Assessment in Patients Suspected of Having Pulmonary Nodules. Radiology 2017; 284: 562-573

[14] Burris NS, Johnson KM, Larson PE et al. Detection of Small Pulmonary Nodules with Ultrashort Echo Time Sequences in Oncology Patients by Using a PET/MR System. Radiology 2016; 278: 239-246

[15] Wielputz MO, Lee HY, Koyama H et al. Morphologic Characterization of Pulmonary Nodules With Ultrashort TE MRI at 3T. Am J Roentgenol 2018; 210: 1216-1225

[16] Nagel SN, Wyschkon S, Schwartz S et al. Can magnetic resonance imaging be an alternative to computed tomography in immunocompromised patients with suspected fungal infections? Feasibility of a speed optimized examination protocol at 3 Tesla. Eur J Radiol 2016; 85: 857-863

[17] Ohno Y, Koyama H, Yoshikawa T et al. Pulmonary high-resolution ultrashort TE MR imaging: Comparison with thin-section standard- and lowdose computed tomography for the assessment of pulmonary parenchyma diseases. J Magn Reson Imaging 2016; 43: 512-532

[18] Mugler JP MC, Pfeuffer J, Stemmer A et al. Accelerated Stack-of-Spirals Breath-hold UTE Lung Imaging. Proc Intl Soc Mag Reson Med. 2017. doi:4904

[19] Qian Y, Boada FE. Acquisition-weighted stack of spirals for fast highresolution three-dimensional ultra-short echo time MR imaging. Magn Reson Med 2008; 60: 135-145
[20] Lustig M, Pauly JM. SPIRiT: Iterative self-consistent parallel imaging reconstruction from arbitrary k-space. Magn Reson Med 2010; 64: 457-471

[21] Hansell DM, Bankier AA, MacMahon $\mathrm{H}$ et al. Fleischner Society: glossary of terms for thoracic imaging. Radiology 2008; 246: 697-722

[22] Attenberger UI, Morelli JN, Henzler T et al. 3 Tesla proton MRI for the diagnosis of pneumonia/lung infiltrates in neutropenic patients with acute myeloid leukemia: initial results in comparison to HRCT. Eur J Radiol 2014; 83: e61-e66

[23] Liszewski MC, Gorkem S, Sodhi KS et al. Lung magnetic resonance imaging for pneumonia in children. Pediatr Radiol 2017; 47: 1420-1430

[24] Torres L, Kammerman J, Hahn AD et al. "Structure-Function Imaging of Lung Disease Using Ultrashort Echo Time MRI”. Acad Radiol 2019; 26: 431-441

[25] Yan C, Tan X, Wei Q et al. Lung MRI of invasive fungal infection at 3 Tesla: evaluation of five different pulse sequences and comparison with multidetector computed tomography (MDCT). Eur Radiol 2015; 25: 550-557

[26] Eibel R, Herzog P, Dietrich O et al. Pulmonary abnormalities in immunocompromised patients: comparative detection with parallel acquisition MR imaging and thin-section helical CT. Radiology 2006; 241: 880-891

[27] Rieger C, Herzog P, Eibel R et al. Pulmonary MRI-a new approach for the evaluation of febrile neutropenic patients with malignancies. Support Care Cancer 2008; 16: 599-606

[28] Letourneau AR, Issa NC, Baden LR. Pneumonia in the immunocompromised host. Curr Opin Pulm Med 2014; 20: 272-279

[29] Lampichler K. [Role of imaging procedures in clarification of complications of pneumonia]. Radiologe 2017; 57: 29-34

[30] Petrusevska-Marinkovic S, Kondova-Topuzovska I, Milenkovic Z et al. Clinical, Laboratory and Radiographic Features of Patients with Pneumonia and Parapneumonic Effusions. Open Access Maced J Med Sci 2016; 4: 428-434 